
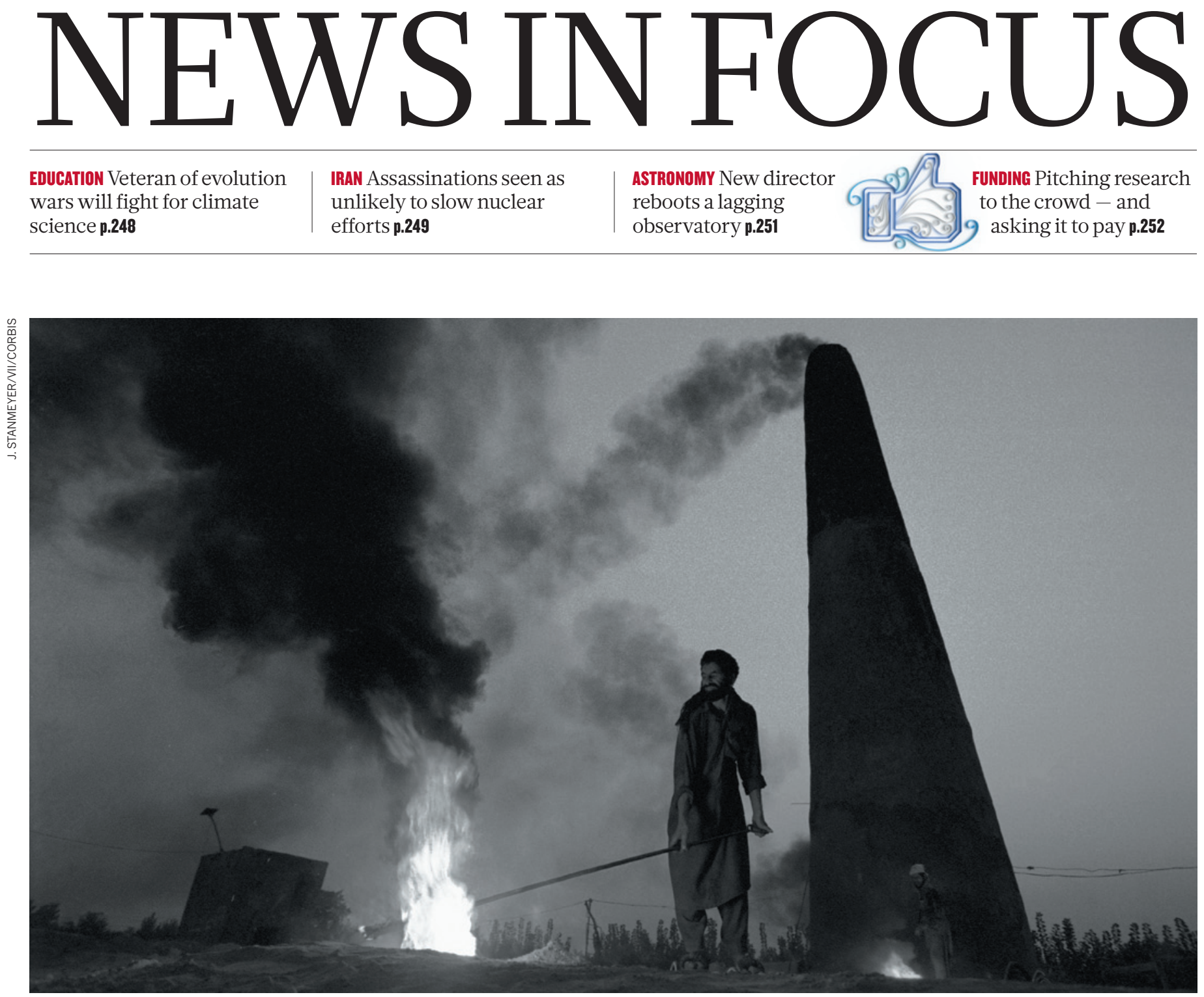

Soot emissions from sources such as this brick kiln in Karkhla, Pakistan, absorb sunlight and contribute directly to global warming.

\title{
Pollutants key to climate fix
}

\section{Governments look to reduce methane and black carbon as a way to slow warming.}

\section{BY JEFF TOLLEFSON}

$\mathrm{B}$ uses spew clouds of black exhaust fumes in Mexico City while, in India, wood burnt in rudimentary stoves fills houses with sooty smoke. Methane leaks from gas pipelines in Russia and rice paddies in China, eventually breaking down in sunlight and contributing to the production of smog and ozone. In each of these cases, simple steps to curb air pollution would promote public health; scaled up, they may offer the only realistic way to tame global warming over the next few decades.

Rapid measures to reduce emissions of black carbon, which soaks up solar energy, and methane, a greenhouse gas that is 25 times more potent than carbon dioxide, could cut the rate of global warming in half between now and 2050, according to an analysis published last week (D. Shindell et al. Science 335, 183-189; 2012). Such numbers have spurred political interest, and next month a small coalition of countries is aiming to launch an initiative that would target these 'short-lived climate forcers'. If successful, the effort could have an immediate impact on global temperatures while countries grapple with efforts to regulate emissions of carbon

\section{DNATURE.COM}

For more on black carbon and its

effects, visit.

go.nature.com/9khxtj dioxide, the most important greenhouse gas.

"We're in a gridlock over carbon dioxide, and we're losing time," says Veerabhadran Ramanathan, an atmospheric scientist at the Scripps Institution of Oceanography in La Jolla, California, and a co-author on the Science analysis. "This is one way to buy back some of that time, and the co-benefits are huge." By 2030, these reduction measures could prevent anywhere from 700,000 to 4.7 million premature deaths from air pollution annually, the study found. And because ozone is toxic to plants, such measures could boost global crop production by $1-4 \%$.

The United Nations Environment 


\section{RAPID RESPONSE}

Measures to reduce emissions of black carbon $(\mathrm{BC})$ and methane $\left(\mathrm{CH}_{4}\right)$ would have an immediate effect on atmospheric warming. Controls on carbon dioxide $\left(\mathrm{CO}_{2}\right)$ are still needed to rein in temperature in the long run.

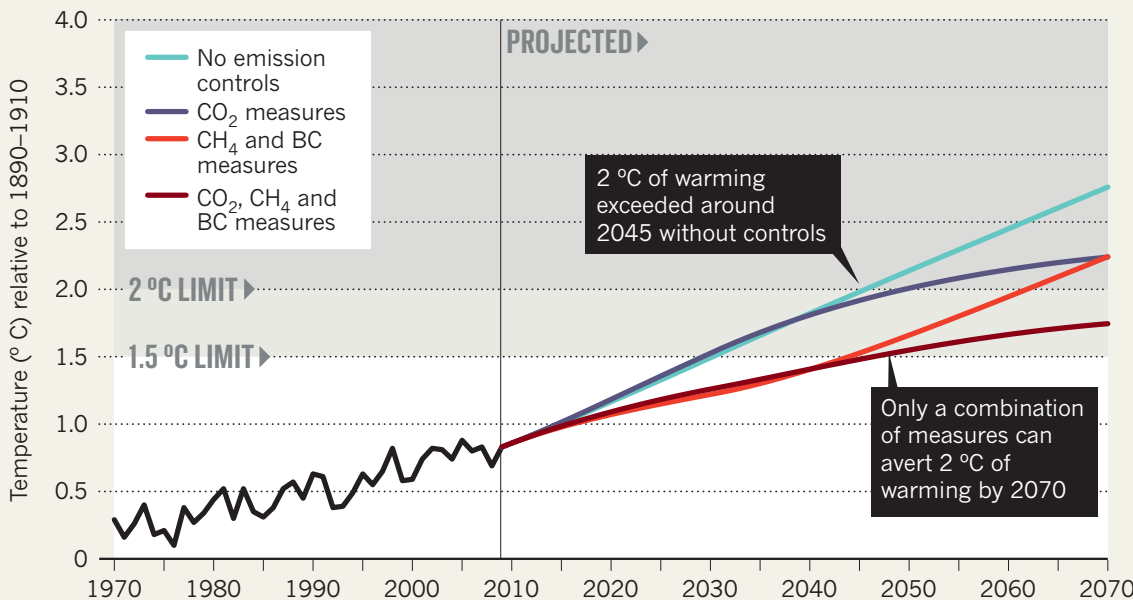

Programme explored the potential gains in a detailed assessment last June (see go.nature. com/4wcwxf). Chaired by Drew Shindell of the NASA Goddard Institute for Space Studies in New York, the assessment ranked hundreds of options for reducing black carbon and ozone pollution according to their potential to reduce warming. A follow-up report, released in November and funded by the Swedish government, further analysed opportunities and impacts at national and regional levels. This work served as the basis for the Science study.

For methane, the study identified 14 control measures that would target leakage from coal mining and oil and gas operations, emissions from landfills, wastewater systems, livestock manure and rice paddies. Black-carbon reduction would focus on cleaning up diesel vehicle emissions, biomass stoves, brick kilns and coke ovens. Other measures would reduce the burning of agricultural waste and provide alternatives to wood, dung and charcoal for cooking and heating in poor countries.

It could take decades to slow global warming through reductions in carbon dioxide emissions, whereas cutting soot and methane would have immediate climate payoffs because they are quickly purged from the atmosphere. Modelling suggests that, together, a 75\% reduction in black carbon and a $40 \%$ reduction in methane emissions over the next two decades would lower projected warming by about $0.5^{\circ} \mathrm{C}$ by 2050 . However, aggressive mitigation of carbon dioxide would still be needed to keep the atmosphere from warming more than $2^{\circ} \mathrm{C}$, the current target of international climate negotiations (see 'Rapid response').

The assessment shows that the benefits of such reductions far outweigh the costs, with premature deaths from pollution predicted to fall the most in India and China. Cuts to black carbon would yield the biggest reduction in warming in Africa, south Asia and the Arctic, where the temperature rise would be reduced by

\section{"This is one of the most important climate agendas for the world right now."}

Kevin Trenberth, a climate scientist at the National Center for Atmospheric Research in Boulder, Colorado, credits the study with building scientific consensus on the issue, but warns that it should not detract from the main agenda on carbon dioxide. "The fundamental problem with long-term climate change is $\mathrm{CO}_{2}$, and anything that takes us away from addressing that doesn't really solve the problem," he says. "It just puts it off."

Advocates concede as much but argue that both tracks are necessary. They point out that the agenda for short-term forcers can move forward now without a global climate treaty, which remains a distant prospect after last month's climate talks in Durban, South Africa, delayed setting new targets for emissions reductions (see Nature 480, 299-300; 2011). Bilateral or multilateral agreements can help to pay for cleaner fuels and filters for diesel engines or promote policies that ban the burning of agricultural waste and promote aeration of rice paddies to decrease methane production. "It doesn't require 150 nations to sign a document," says Ramanathan. "It requires regional partnerships."

In fact, countries exploring methane and black-carbon mitigation are intentionally keeping the agenda separate from the UN climate negotiations. Following initial meetings last year hosted by the United States, Mexico and Bangladesh, these countries, as well as Sweden, Canada and Ghana, are hoping to work out some of the details of an initiative to promote mitigation steps at a diplomatic meeting in Montreal, Canada, next week. The initiative could involve a funding mechanism, a clearing house for projects or even a dedicated organization. "Sweden, Canada and the United States can be expected to put funds into the platform initially," says Caroline Dickson, who heads climate issues at the Swedish environment ministry. "Once we have launched this initiative other countries will be able to join." The goal is to unveil the initiative in Washington DC next month, Dickson says.

The initiative may seek to build on existing efforts. In October 2010, a group of 41 governments and international agencies created the Global Methane Initiative to help poor countries finance profitable methane-capture projects at landfills and other sites. Similarly, last year, various countries and companies launched the Global Alliance for Clean Cookstoves to help improve the quality of stoves in the developing world.

Although the measures under consideration are technically feasible today, aggressive implementation will require high-level political support and broader consideration at international forums such as the G8 and G20 talks, says Durwood Zaelke, who heads the Institute for Governance and Sustainable Development in Washington DC. "My worry is that they are going to undersell it," he says. "This is one of the most important climate agendas for the world right now, but it is not fully appreciated at the highest political levels what it can deliver."

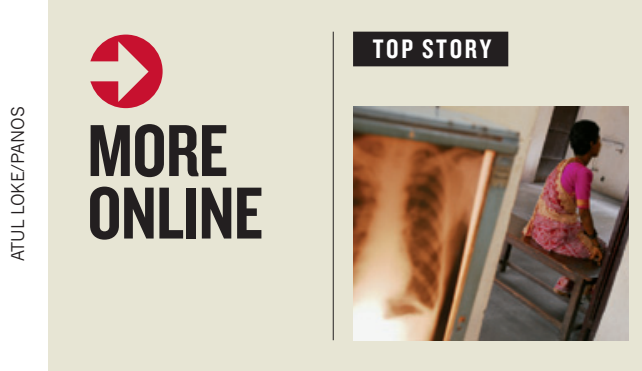

Totally drugresistant TB emerges in India go.nature.com/ vrvgyk

\section{MORE NEWS}

- Multicellular yeast show speed of evolution go.nature.com/3grkip

- British science needs 'integrity overhaul' go.nature.com/dujluo

- Tests to extract methane from gas hydrates begin in Alaska go.nature.com/ mobk76

\section{PODCAST}

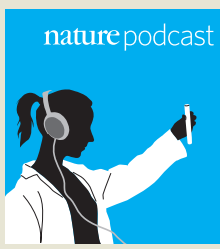

How intelligence ages, science in the Amazon, and crowd-sourcing your research funding go.nature. com/p5vigz 